\title{
VISUALISASI NUGGET LAS TITIK DENGAN METODE ULTRASONIC WATER IMMERSION
}

\author{
Roziq Himawan ${ }^{1}$ dan Inryono Kusuma ${ }^{2}$ \\ ${ }^{1}$ Pusat Teknologi dan Keselamatan Reaktor Nuklir - BATAN \\ ${ }^{2}$ Mahasiswa Program Studi Teknik Mesin, Universitas Katolik Indonesia Atma Jaya
}

\begin{abstract}
VISUALISASI NUGGET LAS TITIK DENGAN METODE ULTRASONIC WATER IMMERSION. Overlay welding merupakan salah satu metode penyatuan dua material yang diterapkan pada bejana tekan reaktor, antara baja feritik dan baja nir karat. Bejana tekan reaktor merupakan komponen utama pembangkit listrik tenaga nuklir, sehingga keandalan dan integritas nya harus selalu terjamin selama umur disainnya. Dalam rangka menjamin keandalan dan integritas bejana tekan reaktor, maka dikembangkan metode ultrasonik dengan teknik water immersion untuk mengevaluasi kondisi hasil overlay welding. Karena keterbatasan sarana, pada penelitian ini overlay welding disimulasikan dengan las titik. Evaluasi dilakukan pada bagian nugget hasil las titik. Evaluasi dilakukan menggunakan teknik water immersion, dimana objek evaluasi direndam di dalam air. Air berlaku sebagai kuplan. Evaluasi menggunakan transduser tipe fokus dengan frekuensi $10 \mathrm{MHz}$ dan diameter fokus $1 \mathrm{~mm}$. Hasil evaluasi ditayangkan dalam bentuk $C$-scan. Dari hasil-hasil evaluasi diketahui bahwa visualisasi memiliki kesesuaian bentuk dengan makrografi nugget yang diperoleh setelah pelaksanaan uji tarik. Namun terdapat perbedaan ukuran antara visualisasi $C$-scan dan makrografi.
\end{abstract}

Kata kunci: bejana tekan reaktor, las titik, metode ultrasonik, water immersion, $C$-scan

\section{ABSTRAK}

VISUALIZATION OF SPOT WELDING'S NUGGET USING ULTRASONIC WATER IMMERSION METHOD. Overlay welding is one of material bonding method applied to reactor pressure vessel, between ferritic steel and stainless steel. Reactor pressure vessel is the main component in Nuclear Power Plant. Thus, the reliability and integrity should be ensured during its design life. In order to ensure the integrity and reliability of reactor pressure vessel, water immersion technique in ultrasonic method was developed to evaluate condition of overlay welding results. Due to limitation, overlay welding were simulated by spot welding. Evaluations were conducted to the nugget area. Evaluations were conducted by using water immersion technique where the evaluation objects were submersed in the water. Water acts as a couplant. Focusing type of transducer was used with the diameter of $10 \mathrm{~mm}$ and the frequency was $10 \mathrm{MHz}$. Evaluation results were presented in $C$-scan. The evaluation results showed that the visualization has geometry conformity with those from nugget's macrograph took after tensile test. But, there were differences in size between $C$-scan visualization and macrograph.

Keywords: reactor pressure vessel, spot welding, ultrasonic method, water immersion, C-scan 


\section{PENDAHULUAN}

Bejana tekan reaktor merupakan komponen utama dari PLTN yang berfungsi sebagai pengungkung bahan radioaktif hasil terjadinya reaksi pembelahan inti atom. Dinding bejana tekan terbuat dari baja tipe feritik yang memiliki sifat mekanik yang sesuai untuk menahan penuaan dari mekanisme tekanan tinggi dan penggetasan neutron. Tetapi, material ini mudah mengalami korosi yang disebabkan oleh air pendingin. Korosi pada dinding bejana ini dihindari dengan memberi lapisan material anti korosi dari jenis baja nir karat austenit. Pemberian lapisan ini disebut cladding. Penggabungan dua material dilakukan melalui proses overlay welding.

Dikarenakan fungsinya yang sangat penting ini, maka keandalan dan integritas bejana tekan reaktor perlu dipastikan dalam kondisi apapun juga. Oleh karena itu, hasil overlay welding merupakan salah satu bagian yang menjadi objek pengujian integritas, baik sebelum reaktor beroperasi maupun dalam kondisi layanan. Terdapat berbagai metode untuk melakukan pengujian baik secara merusak maupun tak merusak. Pengujian secara tak merusak, diantaranya dilakukan menggunakan metode thermografi infra merah, neutron difraktometer dan ultrasonik ${ }^{[1-5]}$. Karena sifatnya yang nonradiasi, metode tak merusak ultrasonik sering digunakan untuk pengujian in-service inspection. Pelaksanaan pengujian ini biasanya dilakukan dengan metode kontak. Berdasarkan kondisi ini, maka dalam penelitian ini akan dilakukan pengembangan metode pengujian ultrasonik dengan non-kontak, yaitu metode water immersion.

Keuntungan metode ini adalah dapat dilakukan tanpa mengosongkan air pendingin yang ada di dalam bejana tekan reaktor. Metode ini telah diterapkan pada penelitianpenelitian sebelumnya ${ }^{[6-9]}$. Pada tahap pengembangan ini, overlay welding pada bejana tekan reaktor disimulasikan dengan spot welding. Hasil pengujian ditayangkan dengan mode $C$-scan. Tujuan penelitian ini adalah untuk mengetahui efektifitas, akurasi, dan faktor-faktor yang mempengaruhi metode $w a$ ter immersion pada pelaksanaan pengujian Spot welding.

\section{TEORI}

Uji tak merusak metode ultrasonik memanfaatkan gelombang ultrasonik untuk menguji material dalam menemukan inhomogenitas. Gelombang ultrasonik memiliki perilaku perambatan yang spesifik tergantung pada material yang dilaluinya. Dalam perambatannya, berlaku hukum-hukum gelombang pada umumnya. Salah satu diantaranya adalah, apabila melewati batas antara dua materi/zat, maka gelombang akan dipantulkan dan diteruskan. Besarnya gelombang yang dipantulkan dan diteruskan, ditentukan oleh koefisien pantul dan koefisien transmisi, yang dinyatakan dengan persamaan berikut ini : 


$$
\begin{aligned}
& R_{S}=\frac{\rho_{2} c_{2}-\rho_{1} c_{1}}{\rho_{1} c_{1}+\rho_{2} c_{2}} \\
& T_{S}=\frac{2 \rho_{2} c_{2}}{\rho_{1} c_{1}+\rho_{2} c_{2}}
\end{aligned}
$$

an ultrasonik dilakukan dengan metode water immersion dengan peralatan sebagaimana diperlihatkan pada Gambar 1. Gambar 2 memperlihatkan foto dan skema ukuran spesimen. Las titik dilakukan dengan dengan variasi waktu (10 dan 20 detik), variasi arus listrik (40 A dan 50 A), dan tekanan konstan sebesar 1,5 bar. Alat ini terdiri dari Ultrasonic Pulser Receiver, Transducer, Osciloscope, $X$-Y table, transducer holder untuk mengatur naik turun transducer dan bak untuk diisi air sebagai media perambatan gelombang ultrasonik dari transduser ke spesimen. Spesimen diletakkan di dalam air.

Ultrasonic pulser-receiver berfungsi membangkitkan gelombang ultrasonik, transducer berfungsi mengubah sinyal elektronik menjadi energi mekanik untuk diteruskan ke spesimen, sedangkan oscilloscope untuk menampilkan sinyal gelombang ultrasonik. material baja karbon selanjutnya dipadukan dengan proses las titik (spot welding). Penguji-

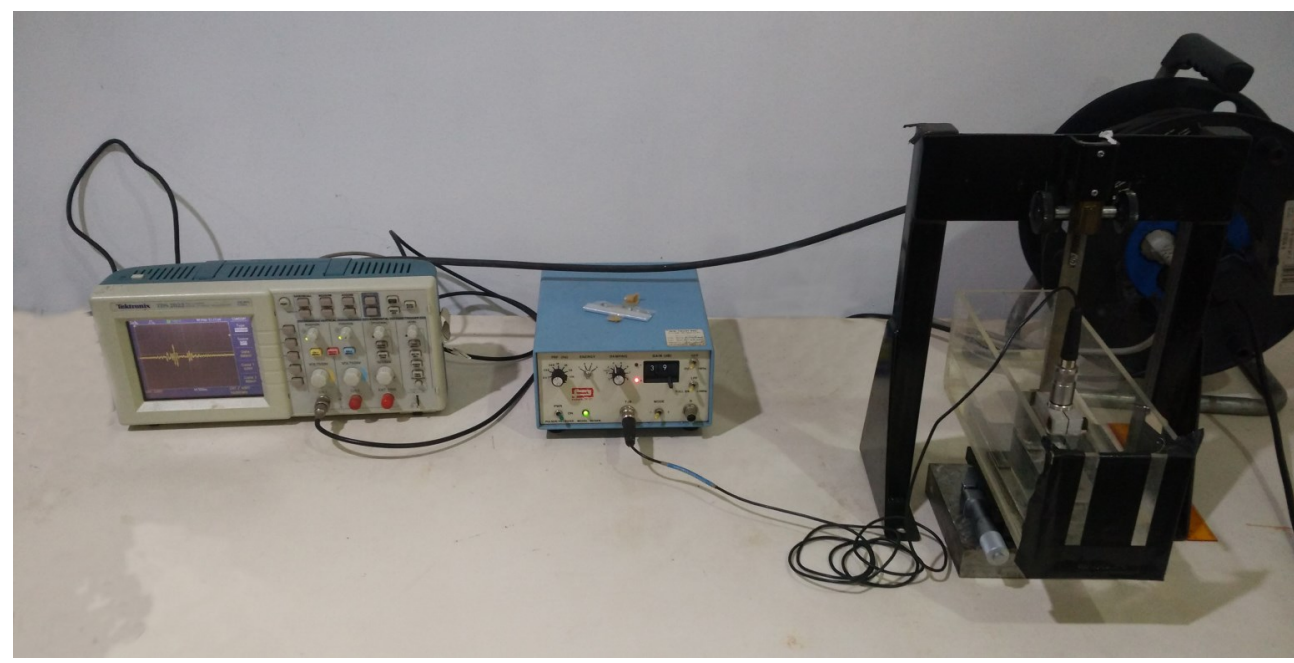

Gambar 1 Alat ultrasonic water immersion untuk visualisasi nugget las titik 

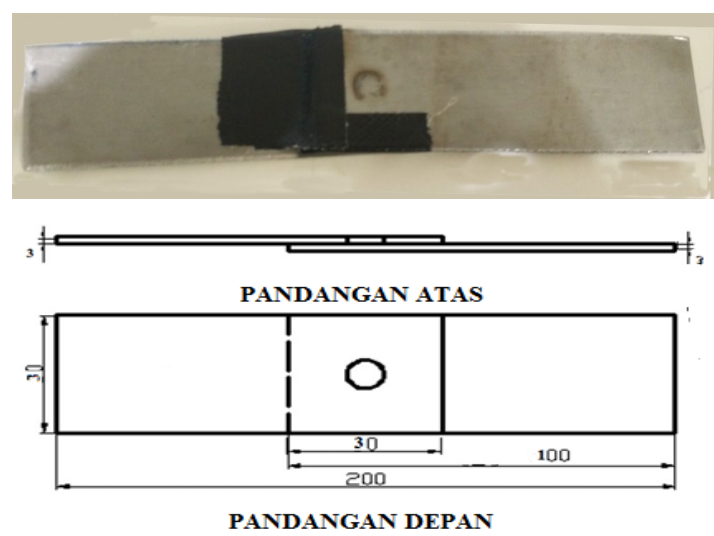

Gambar 2. Foto spesimen las titik dan skema ukurannya

Pengujian dilakukan menggunakan $f_{o-}$ cused transducer dengan frekuensi $10 \mathrm{MHz}$ dan jarak fokus 1 inchi. Pada posisi fokus, sinyal pantul dari permukaan spesimen akan menunjukkan intensitas maksimum apabila jarak antara transducer dengan permukaan spesimen sebesar 1 inchi (lihat gambar 3, atas). Pada posisi ini, back wall echo specimen bagian atas memiliki intensitas yang jauh lebih kecil dibandingkan dengan sinyal gelombang pantul dari permukaan. Intensitas yang lebih besar akan dapat diperoleh dengan cara defocusing, yaitu titik fokus digeser dari yang seharusnya. Dalam penelitian ini, transducer digerakkan mendekat spesimen sedemikian rupa sehingga titik fokus imajiner berada pada permukaan bawah spesimen bagian atas (lihat Gambar 3, bawah). Kondisi ini akan tercapai apabila sinyal backwall echo dari spesimen bagian atas mencapai intensitas maksimum (lihat Gambar 4, sinyal kedua).

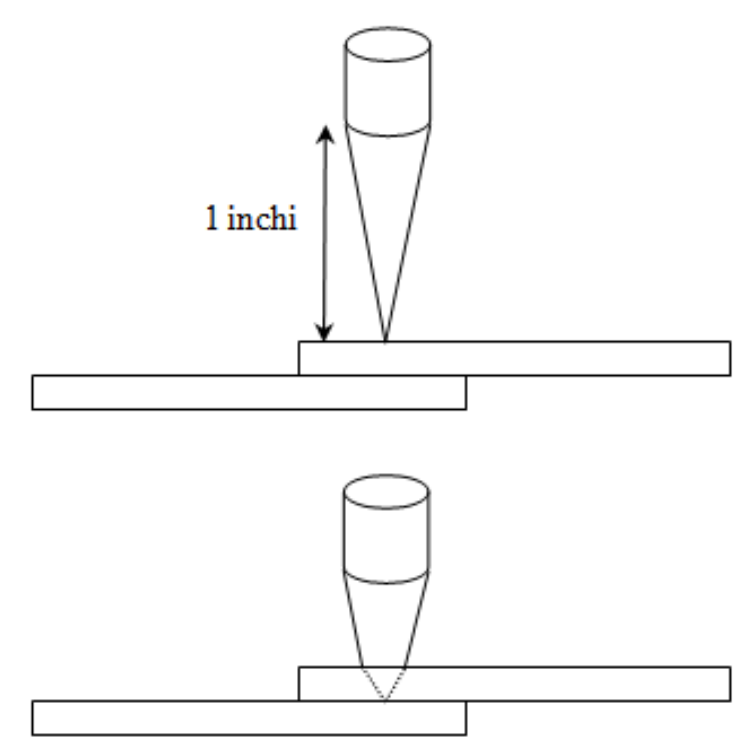

Gambar 3. Posisi defocusing (bawah)

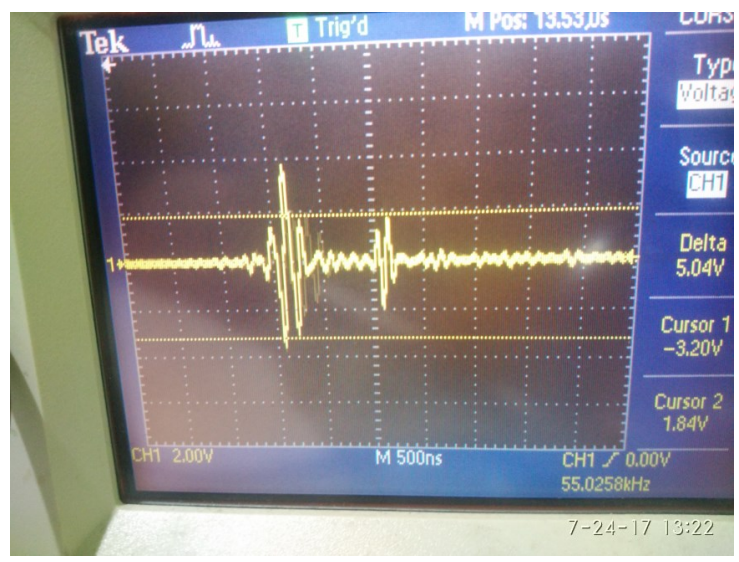

Gambar 4. Kondisi sinyal UT saat titik fokus digeser

Pada kondisi titik fokus digeser ini, dilakukan pemindaian pada area di mana nugget berada (lihat Gambar 2, atas). Area pemindaian memiliki ukuran $15 \times 15 \mathrm{~mm}$. Pemindaian dilakukan menggunakan $X-Y$ table dimana gerakannya dapat diamati dengan mikrometer. Pemindaian dilakukan dengan 
pitch sebesar $1 \mathrm{~mm}$, sehingga dalam pemindaian ini diperoleh data 225 data. Data yang diamati adalah tinggi sinyal dari backwall spesimen bagian atas. Data yang diperoleh selanjutnya ditayangkan secara dua dimensi untuk membuat visualisasi nugget las titik berdasarkan tinggi rendahnya sinyal gelombang pantul. Visualisasi dilakukan menggunakan aplikasi MS Excel.

Untuk memastikan hasil evaluasi ultrasonik, specimen diuji tarik sampai patah, kemu-

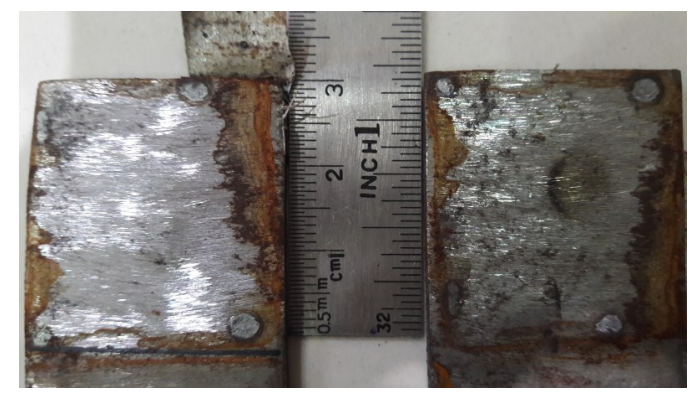

i.a

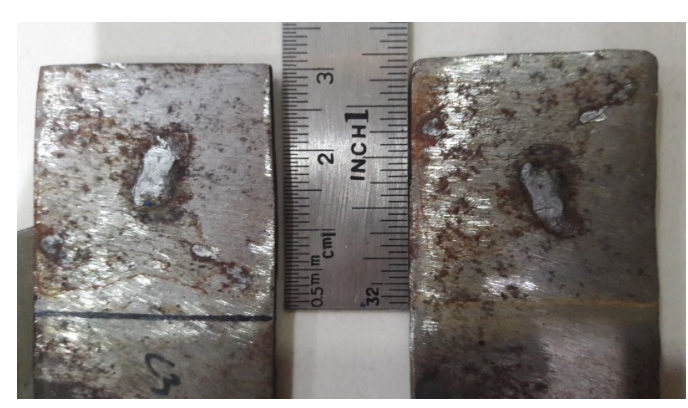

ii.a

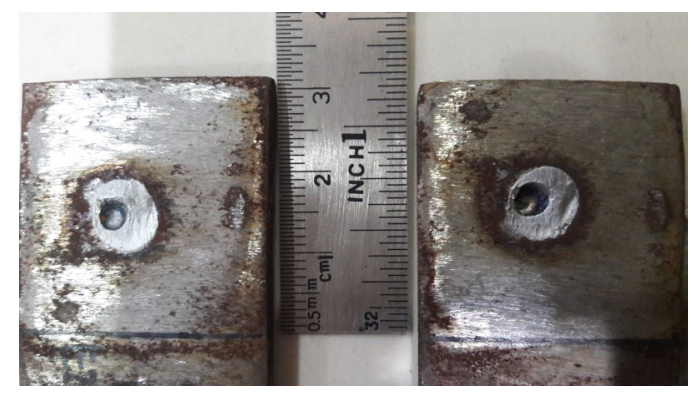

iii.a dian diambil makrografi pada masing-masing bagian nugget. Uji tarik dilakukan menggunakan Universal Tensile Machine.

\section{HASIL DAN PEMBAHASAN}

Hasil evaluasi ultrasonik ditampilkan pada Gambar 5. Sebagai pembanding, pada masing-masing hasil evaluasi ditayangkan juga foto makrografi dari fracture surface hasil setelah spesimen diuji tarik.

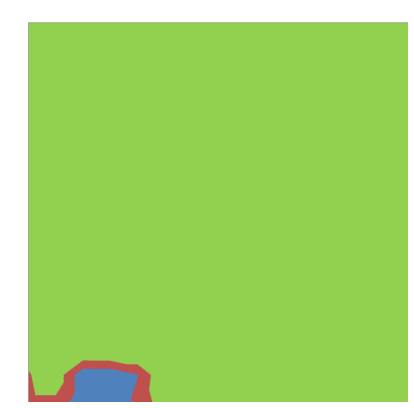

i.b

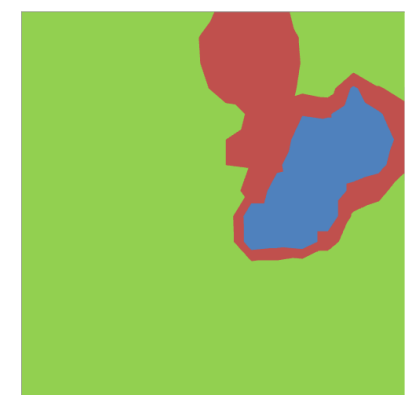

ii.b

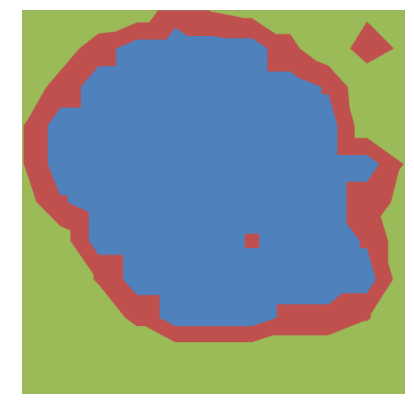

iii.b

Gambar 5. Hasil evaluasi ultrasonik 
Pada Gambar 5 dperlihatkan tiga contoh hasil evaluasi nugget pada alas titik yang diikuti dengan hasil makrografi dengan kamera. Ketiga contoh memiliki kondisi nugget yang berbedabeda, yaitu berturut-turut adalah hasil las titik yang tidak memiliki nugget, hasil las titik dengan nugget namun tidak sempurna, dan terakhir adalah hasil las titik dengan nugget sempurna. Dari ketiga hasil ini kita ketahui bahwa visualisasi hasil evaluasi dengan ultrasonik memiliki kesesuaian dengan makrografi nugget. Ketika nugget tidak terbentuk pada proses las titik, hasil evaluasi dengan metode ultrasonikpun tidak memperlihatkan adanya nugget. Dan, pada saat nugget terbentuk pada hasil proses las titik, baik berbentuk bulat memanjang dan bulat, maka hasil evaluasi dengan gelombang ultrasonic juga memperlihatkan bentuk yang sama. Namun demikian, meskipun bentuk yang dihasilkan memiliki kesesuaian tetapi dalam hal ukuran terdapat perbedaan. Hal ini disebabkan oleh hal-hal sebagai berikut.

a. Sebagaimana telah diuraikan pada bagian metode, bahwa ukuran diameter fokus transducer sebesar $1 \mathrm{~mm}$ dan pitch pemindaian adalah $1 \mathrm{~mm}$, sehingga dengan ukuran pemindaian $15 \times 15 \mathrm{~mm}$, maka resolusi pemindaian ini masih rendah. Dengan demikian, batas-batas ukuran masih tidak jelas.

b. Visualisasi hasil dilakukan dengan program aplikasi MS Excel, dimana dalam visualisasi ini dilakukan konversi nilai numerik ke dalam warna. Sedangkan warna ditentukan dengan kategorisasi berdasarkan rentang nilai numerik. Jadi tidak ada perubahan gradasi antara satu warna ke warna yang lain.

Dari kedua penyebab yang telah diuraikan di atas, untuk memperbaiki tingkat kesesuaian antara hasil visualisasi evaluasi $n u g g e t$ berdasarkan metode ultrasonik dengan foto makrografi, maka dapat dilakukan hal-hal sebagai berikut: i) memperkecil pitch pemindaian. Pada penelitian ini pemindaian dilakukan dengan pitch $1 \mathrm{~mm}$, maka pitch diturunkan misalnya $0,1 \mathrm{~mm}$ atau lebih kecil. Cara ini bertujuan untuk memperbanyak informasi, ii) memperkecil diameter fokus, bertujuan untuk mengoptimasi energi pada area yang lebih kecil untuk membantu peningkatan resolusi, iii) meningkatkan frekuensi gelombang ultrasonik, bertujuan untuk meningkatkan sensitivitas evaluasi, sehingga kondisi nugget dapat dideteksi dengan lebih teliti, antara bagian yang sempurna sampai yang tidak sempurna, iv) pengolahan data citra dengan perangkat lunak khusus yang dapat menampilkan adanya gradasi kondisi nugget.

Dengan keempat metode yang telah diuraikan tersebut, akan dapat memberikan hasil visualisasi hasil evaluasi nugget yang lebih mendekati dengan hasil makrografi fracture surface. Apabila kesesuaian ukuran ini dapat didekati, maka metode ultrasonik teknik water immersion dapat digunakan untuk memprediksi kekuatan hasil las titik. Karena, kekuatan hasil las titik ditentukan oleh kondisi nugget yang terbentuk. 


\section{KESIMPULAN}

Telah dilakukan evaluasi nugget hasil las titik material baja karbon dengan metode ultrasonik teknik water immersion. Proses las titik dilakukan dengan memvariasikan waktu penekanan elektroda dan besarnya arus listrik, untuk memperoleh variasi kondisi nugget. Hasil -hasil evaluasi nugget yang ditayangkan secara visual (C-scan) menunjukkan bahwa metode ultrasonik teknik water immersion efektif digunakan untuk mengevaluasi hasil las titik. Meskipun hasil secara $C$-scan dapat memperlihatkan bentuk nugget yang sesuai dengan bentuk aslinya, namun secara ukuran terdapat perbedaan.

\section{UCAPAN TERIMA KASIH}

Penulis menyampaikan terima kasih kepada Pusat Teknologi dan Keselamatan Reaktor Nuklir atas dukungan finansial sehingga terlaksananya penelitian ini. Ucapan terima kasih penulis sampaikan juga kepada para staf Bidang Pengembangan Fasilitas Keselamatan Reaktor-PTKRN-BATAN, yang telah mempersiapkan spesimen dan pelaksanaan uji tarik.

\section{DAFTAR PUSTAKA}

1. J. Schlichting, S. Brauser, L.A. Pepke, C. Maierhofer, M. Rethmeier, M. Kreutzbruck, NDT\&E International 48, 23 - 29 (2012).

2. D. Min, S. S. Liu, H. Hong, P. Tao, P. L. Zhang, Materials and Design, 52, 353 358 (2013).

3. R.S. Florea, C.R. Hubbard, K.N. Solanki, D.J. Bammann, W.R. Whittington, E.B.
Marin, Journal of Materials Processing Technology 212, 2358 - 2370 (2012).

4. A.M. Safi, M. A. Salam Akanda, J. Sadique, and M. S. Alam, Procedia Engineering 90, 110 - 115 ( 2014 ).

5. M. Thornton, L. Han, and M. Shergold, NDT\&E International $48,30-38$ (2012) .

6. Winarta Dennis, Perbandingan Uji Ultrasonik Antara Metode Kontak Dengan Metode Water Immersion Untuk Prediksi Kualitas Hasil Las Titik Pada Material Yang Berbeda, S1 Final Project, Universitas Atma Jaya Jakarta, 2014.

7. R. Himawan, E. Tsuchida, Y. Arai, Measurement of Internal Geometry of Small Surface Crack by Ultrasonic Method, NII-Electronic library Service, Vol. 45, No. 4, pp. 610-611 (2002).

8. R. Himawan dan M. Farokhi, Jurnal Teknologi Bahan Nuklir 91 (2008).

9. R. Himawan and M. Haryanto, Proceeding of the 2nd International Conference on Nuclear Energy Technologies and Sciences, (2017) (on Press). 